\title{
PRECIPITATION DEFICITS IN THE NETHERLANDS ${ }^{1}$ )
}

\author{
A. SONNEVELD
}

Institute for Biological and Chemical Research on Field Crops, Wageningen

\section{SUMMARY}

ThonnthwaIte's method was used to calculate the precipitation deficiency for the individual years 1921 to 1950 inclusive over the whole growing season of 176 places uniformly distributed throughout Holland. It was found that fairly considerable variations may occur between the mean precipitation deficiency in various parts of the country. There are, however, even greater differences in the frequency with which marked deficiencies occur. Attention is drawn to the need for more exact data.

\section{INTRODUCTION}

Holland is a notoriously watery country, and its annual rainfall can certainly not be called low. Nevertheless the conviction that precipitation deficits injurious to agriculture are a more or less frequent occurrence has gained rapid ground during the last decades. These deficits are not felt to the same extent in all parts of the country; it chiefly depends on the character and altitude of the soil, but differences in the amount of precipitation are also a factor, as will be shown below.

Although arable crops may also suffer from drought, it is mainly on grassland that the results of precipitation deficiencies are felt. Observations and experiences during the dry years of 1947 and 1949 created the need for more detailed information, where possible, on the incidence of precipitation deficits.

The latter were calculated with the aid of the method devised by the American climatologist Thornthwarte (1931) and subsequently improved on (1948). ThonNthwaIte employed this method in order to designate the climatic types in as many parts of the world as possible, so as to provide a better classification of the climates occurring over the earth as well as an improved method of determining their distribution.

He was consequently obliged to strictly limit the number of results of meteorological observations employed in his calculations, the only ones made use of being temperature, and precipitation and the distribution thereof over the year. In fact, these are the only two meteorological magnitudes which are observed throughout the world on an extensive and regular scale. True, other meteorological magnitudes have been determined on a wider scale since the last war, but longer series of observations on which a classification of climate could be based are only available to a very limited extent in large parts of the world.

Potential evapotranspiration, or the amount of water used by a plant cover under ideal conditions of soil and vegetation moisture, (see also vaN WIyk et al., 1953), is determined in ThoRNTHwaITe's method on the basis of an empirical correlation with the mean monthly air temperature. At the same time correction factors are employed for the latitude.

Another method of determining potential evapotranspiration was published by the Englishman Penman in the same year (Penman, 1948). It is entirely

1) Received for publication January 15, 1957. 
based on physical principles and is undoubtedly better and more precise than Thornthwaite's method. A drawback of Penman's method is that more meteorological data are required for making the calculation, i.e. temperature, relative humidity, cloudiness and wind velocity. This calculation gives the evaporation from an open water surface. The rate of evaporation from a surface covered with vegetation is estimated from the value thus found by multiplying it by an empirical conversion factor, or by means of a calculation on a physical basis which takes into consideration stomatal resistance to diffusion and night closure of the stomata (PENMAN, 1952).

When Penman's method became known to us a good many of the calculations on which the following is based had already been made. We therefore continued to use Thornthwarte's method, despite the increasing number of objections that were being raised against it; this also explains why our findings were not published earlier. However, in view of the interest that continues to be shown in these results in various quarters we are summarising them below.

\section{Material and Methons of calculation}

Using ThовNTнWAITE's method, the potential evapotranspiration for each year from 1920 to 1950 inclusive was calculated for the twelve main and substations referred to in the Monthly Survey of Weather Conditions in Holland. The resultant mean figures for these years are listed in Table 1.

Table 1 Potential evapotranspiration in $\mathrm{mm}$ of a number of weather stations in Holland for individual months and the whole year, calculated according to THORNTHWAITE's method (mean figures for the period 1920 to 1950 inclusive).

\begin{tabular}{|c|c|c|c|c|c|c|c|c|c|c|c|c|c|}
\hline Station & J. & F. & M. & A. & M. & $\mathrm{J}$ & J. & A. & $\mathrm{S}$. & O. & $\mathrm{N}$. & D. & Year \\
\hline Den Helder & 10 & 11 & 22 & 42 & 73 & 97 & 115 & 105 & 79 & 49 & 23 & 12 & 637 \\
\hline Akkrum, Rottum, Joure & 7 & 9 & 22 & 44 & 78 & 101 & 117 & 105 & 75 & 44 & 19 & 7 & 628 \\
\hline Groningen $\ldots$ & 7 & 9 & 23 & 45 & 80 & 101 & 118 & 106 & 76 & 45 & 19 & 8 & 637 \\
\hline Hoorn .... & 9 & 11 & 23 & 45 & 78 & 100 & 117 & 105 & 76 & 46 & 21 & 9 & 640 \\
\hline Avereest, Den Hulst, & & & & & & & & & & & & & \\
\hline $\begin{array}{l}\text { Wijster, Witteveen } \ldots \\
\text { Katwijk a/d Rijn, }\end{array}$ & 7 & 9 & 23 & 45 & 79 & 100 & 116 & 103 & 74 & 43 & 18 & 7 & 624 \\
\hline Naaldwijk $\quad . . \ldots$ & 9 & 11 & 24 & 46 & 78 & 100 & 117 & 105 & 77 & 47 & 22 & 10 & 646 \\
\hline De Bilt & 8 & 10 & 25 & 47 & 81 & 104 & 119 & 106 & 76 & 45 & 19 & 8 & 647 \\
\hline Winterswijk & 8 & 9 & 24 & 47 & 81 & 103 & 119 & 106 & 75 & 43 & 18 & 7 & 640 \\
\hline Flushing & 11 & 12 & 25 & 45 & 77 & 100 & 117 & 107 & 79 & 49 & 24 & 11 & 656 \\
\hline Oudenbosch & 9 & 12 & 26 & 48 & 81 & 102 & 117 & 105 & 76 & 45 & 20 & 9 & 650 \\
\hline Gemert & 8 & 10 & 26 & 48 & 83 & 105 & 121 & 107 & 76 & 44 & 19 & 8 & 654 \\
\hline Maastricht & 10 & 12 & 28 & 49 & 84 & 107 & 125 & 110 & 79 & 45 & 21 & 9 & 677 \\
\hline Holland, average & 9 & 10 & 24 & 46 & 79 & 102 & 118 & 106 & 77 & 45 & 20 & 9 & 645 \\
\hline
\end{tabular}

The least evapotranspiration is found to occur in the north-east of Holland; on the other hand, it is above the average along the coast (except for the extreme north-west), in the middle of the country, and particularly in the south-east.

A similar distribution over the country was found by KrAMER (1954) in his study of evaporation in 1953 by means of evaporation meters as used bv PICHE. The differences found by KraMER were, however, much greater (it should be borne in mind that his observations related to a single year only), although 
there is no doubt that the variations found in calculations based on THORNTHWAITE's technique are too small. KRAMER points out in his article that values calculated in accordance with PENMAN from monthly figures often tend to tone down the extremes to a certain extent. Despite this his calculations based on Penman showed that there was still a greater difference between the north and south of the country than appears from calculations according to THORNTHWAITE. It is therefore believed possible to take for granted that evapotranspiration is higher in the south of Holland than in the north, and that the difference found in calculations according to ThonNthwaIte is too small. This question will be referred to again below.

More or less complete data was available for the period from 1920 to 1950 inclusive from 176 rain stations distributed over the entire country. During this period certain stations were in fact closed down, but in such cases a new station was frequently opened in the immediate vicinity. The continuous series of such successive stations were only used when the distance between them was not more than a few kilometres. When for any reason the rainfall at a station during any given month was not available the mean of the three neighbouring stations was taken instead. Care was taken to ensure that these stations were distributed as regularly as possible around the one to be supplied. In these additions, which were only very slight in extent, use was also made

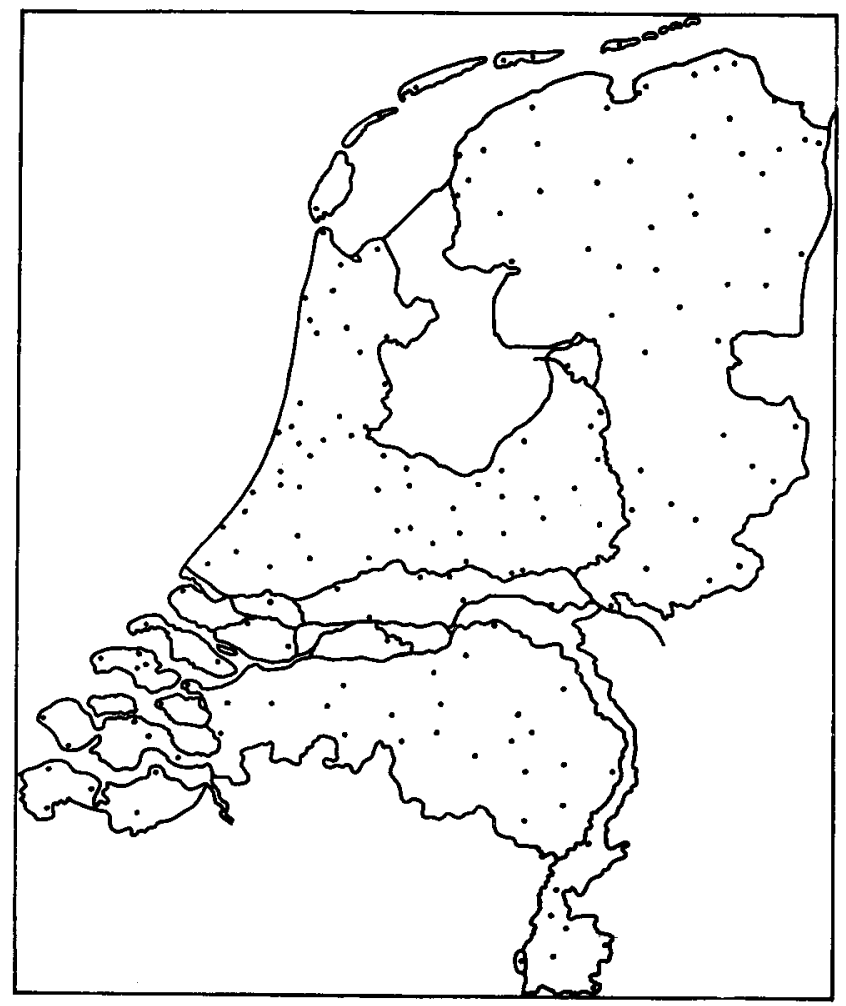

Fig, 1 Distribution over Holland of the places where precipitation deficiency WAS ESTİMATEd. 
of stations where the entire series of observations was either too brief or incomplete to be utilised.

The rain stations were divided into groups round the main and substations on the same system as that employed by the Royal Netherlands Meteorological Institute ("rain provinces").

Using ThoRNTHWaITE's method, the water deficiency for each station or such a group was then calculated for each of the years 1921 to 1950 inclusive from the potential evapotranspiration of the corresponding main or substation and the rainfall at the station itself. The amount of soil moisture available for plant growth has also to be taken into account. This value is assumed to $100 \mathrm{~mm}$ in all cases. This is no doubt too low for a clayey or loamy soil with good moisture-retaining properties, but on the other hand it is too high for a light sandy soil retaining little moisture. Moreover it makes a great difference whether the vegetation cover consists of a cereal or root crop with a fairly rough and deeply penetrating root system, or old grassland with a great number of finer roots remaining closer to the surface. $100 \mathrm{~mm}$ will, however, be an approximately correct average, and this figure is in fact often found in the literature. Fig. 1 shows the distribution over the country of the stations on which the calculation is based.

\section{Results}

In making the estimates it is important to know whether the water in storage in the soil was fully supplied in the course of the preceding winter. This explains why various estimates were made for 1920 but that the first estimate of water deficiency is in respect of 1921. As a result of these calculations the water deficiencies at 176 stations uniformly distributed over the country were defined for 30 separate years. The average deficiency over the 30 -year period was calculated for each station. These averages were used to compile the map shown in Fig. 2. It can be seen from this map that there are marked variations in precipitation deficiency, the maximum being $\pm 100 \mathrm{~mm}$. This is chiefly because in districts in which potential evapotranspiration was found to be relatively high (the south-eastern region) the precipitation during the summer in particular is less than the average for the whole country. On the other hand, the precipitation in the north-east of Holland is greater than the average for the country, while it was found that the potential evapotranspiration is relatively low. We have already pointed out above that in the calculation according to THORNTHWAITE the differences in potential evapotranspiration appear smaller than they are in reality. Consequently the differences in precipitation deficiency between the north and south of the country will no doubt be somewhat greater than appears from Fig. 2.

Fig. 2 is open to a number of objections. The precipitation deficiencies recorded at the individual stations are divided into small classes, with the result that the deficiencies at a good many stations are just under or over a boundary line, and the area surrounding such a station was recorded as belonging to a different class. This makes the map more detailed than is actually necessary. Then there are stations where the rain gauges are no doubt wrongly arranged, or were in the past, with the result that the precipitation recorded was systematically too high or too low. But a number of details are certainly reliable where they are based on the results reported by two or even more stations. In spite of these shortcomings the map in Fig. 2 has been included 


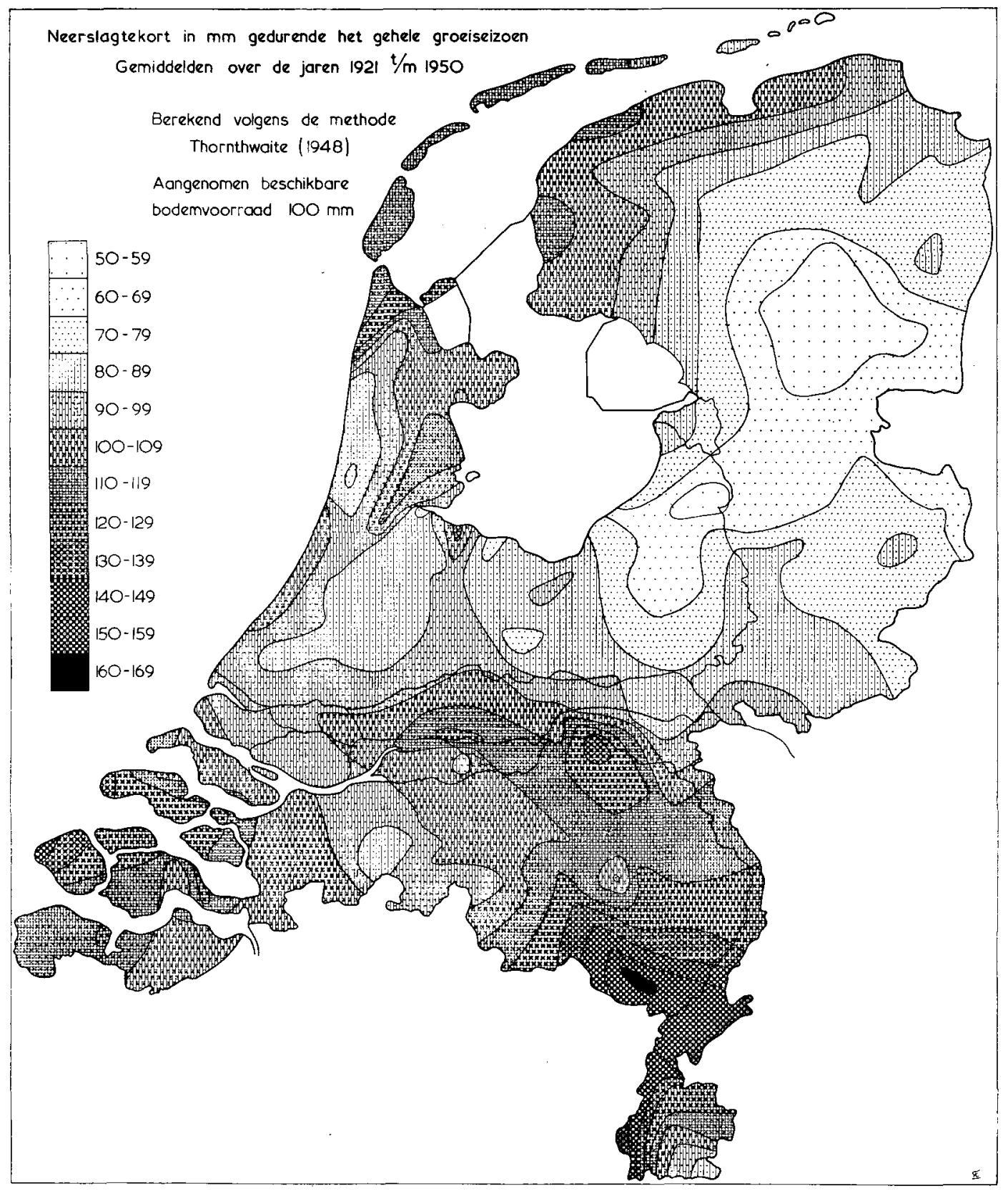

Fig. 2 Pinecipitation deficiency in MM DuRing the Wiole of the growing SEason For THE PERIOD 1921-1950 INCIUSIVE.

The soll Moisture available to the plant is estimated at 100 MM. 


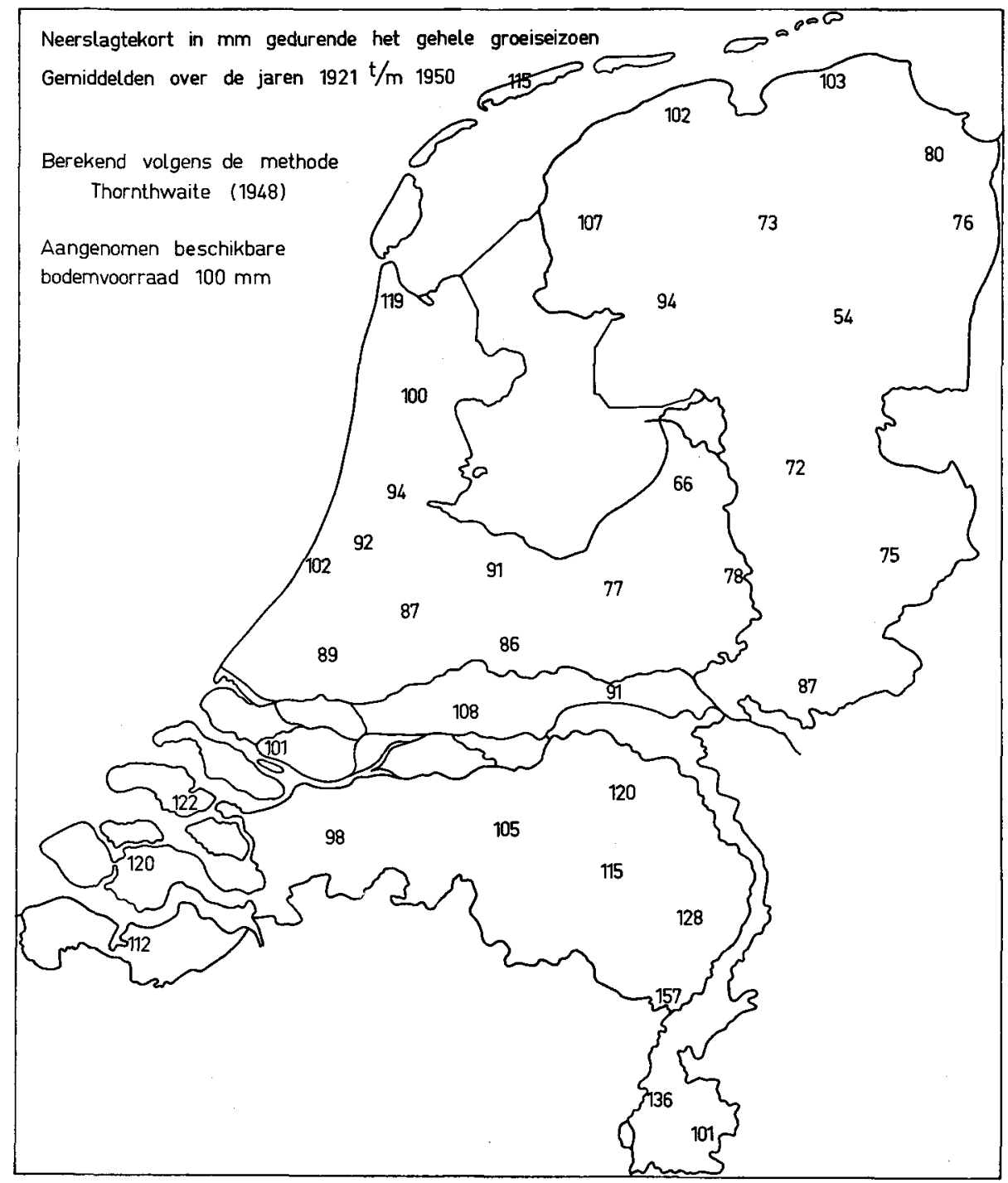

FIG. 3 As IN FIG, 2; SEE TEXT.

in order to demonstrate the reservations that should be made when basing one's deductions on the results of a single station. Even where it is only required to gain an idea of the situation in a comparatively small area it will be necessary to consult the data provided by several observation points in this area or its immediate vicinity.

A much truer picture is obtained by assembling the data from a number of neighbouring observation points, as is done in Fig. 3. The mean precipitation deficiency was calculated for each group of five stations and this mean figure shown on the map. In each case the figure is recorded in the centre of the observation points from which it was calculated. In a number of cases where there were fairly great differences between observations made at short 


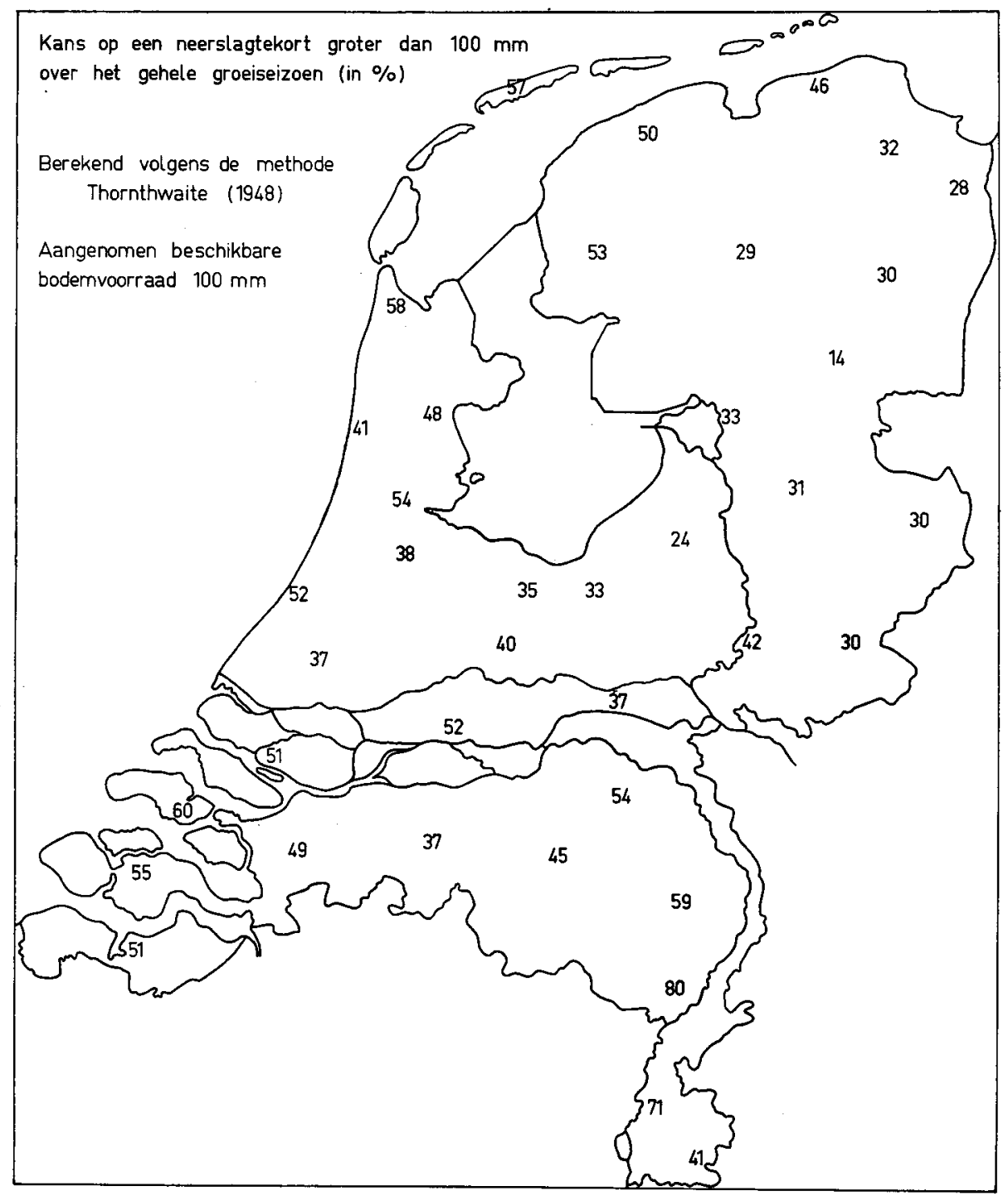

Fig. 4 The chance in \% OF a precipitation Deficiency Greater than 100 MM over the WHOLE OF THE GROWING SEASON.

The soll moisture available to the plant is estimated at $100 \mathrm{Mm}$.

distances from each other the mean was exceptionally calculated from less than five stations (e.g. South Limburg). In these cases it was impossible to find groups of five stations within which the individual figures were not too wide apart.

In spite of the map being so greatly over-simplified it still shows very clearly the differences between precipitation deficiencies in one part of the country and another.

As was mentioned above, the precipitation deficiency was estimated for each 


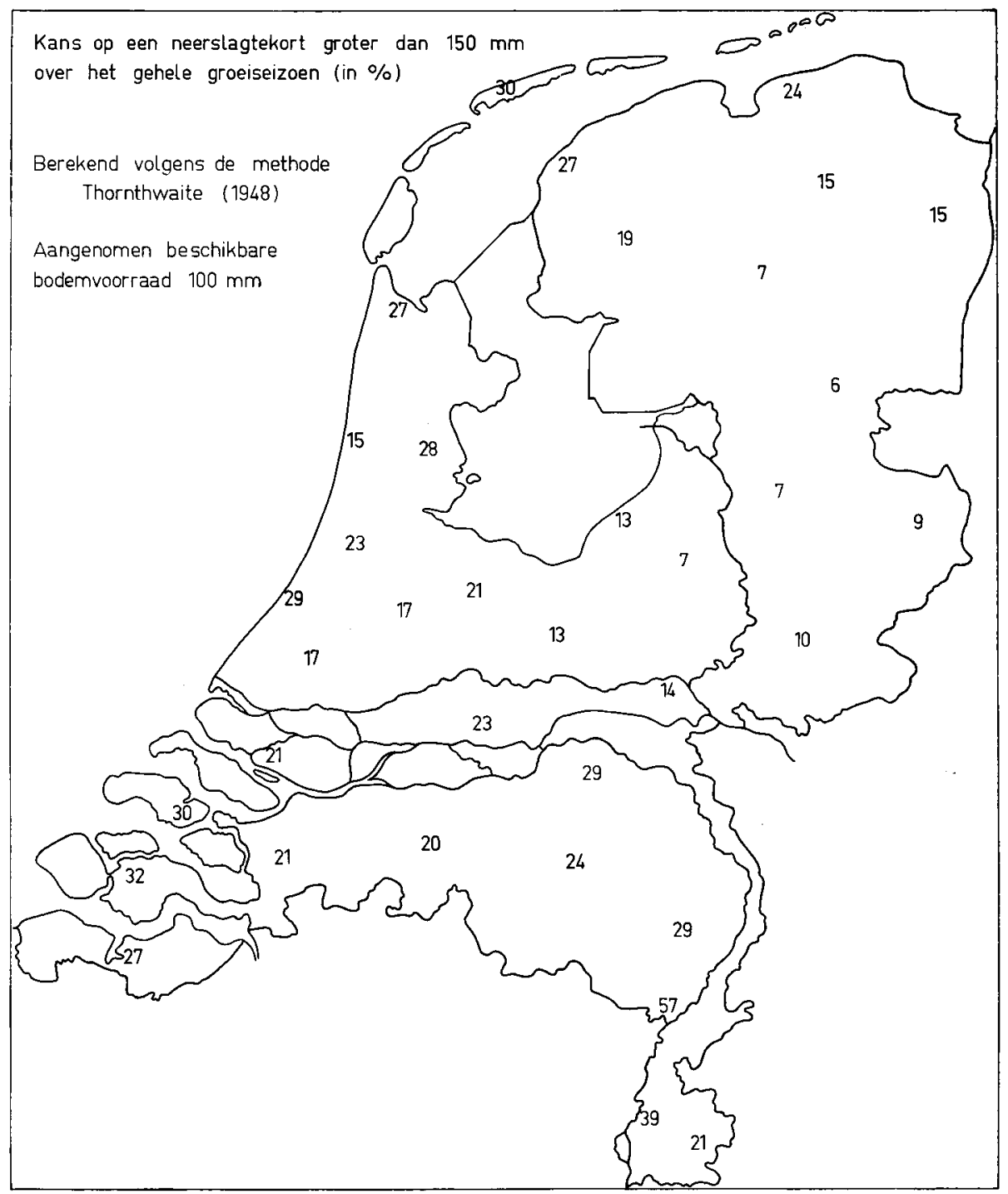

Fig. 5 The chance in $\%$ of a precipitation deficiency greater than 150 mM over the WHOLE OF THE GROWING SEASON.

The soll moisture avallable to the plant is estmated at $100 \mathrm{MM}$.

separate year of the period 1921-1950 inclusive in respect of all 176 rain stations included in the calculation. This also makes it possible to estimate the chance of the precipitation deficiency for each separate station exceeding a given limit. The results of the estimation are listed in Figs. 4 and 5 which show the percentage chance of the precipitation deficiency being greater than 100 and $150 \mathrm{~mm}$ throughout the growing season.

In order to avoid unwarranted details these figures show, as in Fig. 3, the mean value of a number of neighbouring observation points. The groups from 
which the mean values are calculated are not the same as those utilised in Fig. 3. The differences between the various parts of the country are shown more clearly in Figs. 4 and 5 than in Fig. 3. This is important for estimating whether any steps taken to reduce the harmful effects of precipitation deficiencies are likely to be worthwhile.

The above material only relates to the precipitation deficiency throughout the season, so that the results are chiefly valuable for grassland, viz. the only important crop that stands throughout the growing season and for which it is very important to have ideal conditions of moisture throughout the season. It may be questioned whether an available store of soil moisture of $100 \mathrm{~mm}$, as assumed in the calculations, is not too large. In several kinds of soil, e.g. light or elevated soil, the value is certainly excessive. It may therefore be assumed that the figures relating to such soils are excessively low values. It was not thought necessary to allow for this in assembling the figures as there may be a great diversity of soil types within a comparatively short space.

\section{CONCLUSION}

ThonNThwaIte's method is less suitable for obtaining accurate data on the precipitation deficiency in small areas and areas at a short distance from each other, nor is this the purpose for which it was intended. It was devised in order to provide, from the data available, the most rational classification possible of climatic types occurring over the whole earth. Since this method is based on temperature it leads to an appreciable time-lag for estimates of potential evapotranspiration, the highest and lowest temperatures actually occur a considerable time after the summer and winter solstice (see also vas $W_{I J K}$ et al., 1953). This does not completely falsify the estimates given above as in all cases it was the deficiency over the whole growing season that was calculated, and the distribution of the deficiency over this season was ignored. Moreover Thonnthwatte's method tends to level out differences in potential evapotranspiration.

Even allowing for all the drawbacks attaching to THORNTHWarTE's method considerable differences were found in precipitation deficiencies between the various parts of the country, so that any attempt to provide more exact data must be regarded as a very worthwhile undertaking.

The relatively great differences in precipitation deficiencies are due to the fact that in certain areas relatively low evapotranspiration is accompanied by a relatively large rainfall during the growing season, whereas in other areas it is the relatively high potential evapotranspiration that is together with relatively low precipitation during this season.

If it is desired to know the precipitation deficiency at a given place or in a comparatively small area the method of basing estimates on observations made at one point only is to be deprecated. This is particularly important in the case of rainfall observations. In order to judge whether any steps taken to eliminate precipation deficiencies are likely to be successful it is important to note that the above estimates show that the differences in the frequency with which marked deficits occur are even greater than the differences in the mean deficit.

Any efforts to provide more exact data on this matter also are certainly to be encouraged. 


\section{REFERENCES}

Kramer, C.: Onderzoek naar de invloed van neerslag en verdamping op de dagelijkse fluctuaties van de grondwaterstand. Wetenschappelijk Rapport, W.R. 54-002 (III-135), K.N.M.I., De Bilt (1954).

Penman, H. L. : Natural evaporation from open water, bare soil and grass. Proc. of the Royal Soc., A. 193 (1948) 120-146.

- - : The physical bases of irrigation control. Report of the Thirteenth International Horticultural Congress, London (1952) 913-924.

Thonnthwarte, C. W.: The climates of North America according to a new classification. The Geogr. Rev., 21 (1931) 633-655.

- - : An approach toward a rational classification of climate. The Geogr. Rev., 38 (1948) $55-94$.

WiJk, W. R. van, D. A. de VRIEs and R. H. A. VAn Duin : Potential evapotranspiration. Neth. J. of Agr. Sci., I (1953) 35-39. 